\title{
LAZER, MEIO AMBIENTE E EDUCAÇÃO FÍSICA ESCOLAR: RELAÇÕES POSSÍVEIS? *
}

\author{
Giuliano Gomes de Assis Pimentel \\ Universidade Estadual de Maringá, Maringá, Paraná, Brasil \\ Evando Carlos Moreira \\ Universidade Federal de Mato Grosso, Cuiabá, Mato Grosso, Brasil \\ Raquel Stoilov Pereira \\ Centro Universitário de Várzea Grande, Várzea Grande, Mato Grosso, Brasil
}

\begin{abstract}
Resumo
Este ensaio objetiva discutir relações existentes e viáveis de serem concretizadas entre Lazer, Meio Ambiente e Educação Física no âmbito escolar. Para tanto, pondera sobre a necessidade de compreendermos o Meio Ambiente na condição de lugar onde se vive e convive. Em consequência, a Educação Física pode inicialmente tratar pedagogicamente de seus conteúdos em relação aos desafios concretos materialmente presentes no cotidiano da comunidade. Nessa perspectiva, se discute esse aprendizado a partir da escola, propondo encaminhamentos em cada nível de ensino.
\end{abstract}

Palavras-chave: Atividades de Lazer. Meio Ambiente. Ensino Fundamental e Médio.

\section{Introdução}

Saí pra ver o luar,

Pensando no que iria encontrar, Encontrei as mais lindas estrelas.

Procurei então uma floresta,

Só fui perceber no fim,

Que a floresta estava dentro de mim.

\begin{abstract}
A epígrafe acima foi retirada do poema "Uma floresta encantada", redigido por uma aluna da sétima série, de um colégio público do Centro-Oeste brasileiro. Seu conteúdo expõe alguns chavões com que nossos jovens são formados para compreender o tema meio ambiente, indo do empírico imediato ao subjetivismo, sem passar pelas
\end{abstract}

* O presente trabalho não contou com apoio financeiro de nenhuma natureza para sua realização. 
determinações presentes na nossa relação com o meio. Enfim, o plano das relações com as estruturas sociais é subtraído por ideações sobre um ambiente, quase sempre reduzido à natureza.

Sobre o contexto de criação do poema, se infere a dificuldade da escola em superar a apreensão idealista do conteúdo ambiental, visto que, em termos de estratégias de abordagem da temática, a escola continua seguindo o rito de eventos especiais (Semana do Meio-Ambiente, Gincana ecológica, entre outros do gênero), cuja eficácia é questionável, transformando o evento em vento.

Para ilustrar a recorrência da tradição da escola em celebrar o meio-ambiente, há 30 anos, quando crianças, presenciávamos campanhas, na escola pública, sobre a possibilidade do petróleo se esgotar. Que terror se apoderava de nós em imaginar o fim do petróleo no mundo! De fato, parece que o meio ambiente é só exterioridade e a natureza algo para se usar e que só tem valor quando está prestes a se extinguir. Porém, essa relação instrumental e utilitária aliena a consciência acerca da complexidade e a dialética das relações do sujeito social com o par ambiente - natureza.

Como bem ensinou Marx, é na natureza que o homem se objetiva e, ao se objetivar, se humaniza. Assim, ele constrói e muda seu ambiente. Sendo o trabalho, na sua forma mais concreta, a transformação da natureza pelo ser humano, seria primordial que o coletivo das forças produtivas governasse de modo racional o metabolismo humano com a natureza. Mas, como se sabe, o capitalismo, não alçou formas de um equilíbrio entre a satisfação das necessidades e o uso humanizado das matérias-primas. Pelo contrário, somente aprofundaram as desigualdades, responsabilizando a natalidade dos pobres como causa dos problemas ambientais. (FOSTER, 2005).

Neste sentido, a escola não pode se furtar em ensinar crianças e jovens sobre a intricada relação do modo de produção da vida social com o meio ambiente, porém, numa perspectiva crítica e transformadora. Isso não se deflagra com trabalhos isolados numa ou outra disciplina, sendo fundamental a participação de todos os conhecimentos escolares, inclusive a Educação Física. Sobre o enraizamento da área na educação ambiental concordamos com Souza e Lara (2011, p. 9) sobre a necessidade de "uma prática pedagógica que situe o âmbito de conhecimento da cultura corporal nas condições de vida real". Para tanto, defendemos neste texto teses e linhas de trabalho diretas e singelas, orientadas para uma intervenção em relação à discussão sobre a 
temática ambiental na organização curricular da Educação Física curricular.

\section{Ideias principais}

Um primeiro conceito importante para se observar é a aproximação que os Parâmetros Curriculares Nacionais - PCNs trouxeram entre Saúde e Meio Ambiente, apresentando tópicos interessantes para o trabalho escolar nesses temas transversais. Contudo, conforme já criticamos (PIMENTEL, 2002, 2006), as propostas vigentes, tanto no turismo quanto na educação, ainda pouco apontam para as causas do problema, sendo muito focadas em consequências e limitadas atenuações do problema ambiental. Seria necessário, como no poema em epígrafe, que, inicialmente, as pessoas despertassem para o fato do meio ambiente ser composto por nós, pois como a terra cuidada se torna agricultura, nós somos seres da natureza que fazem cultura.

Embora essa 'conscientização' deva ser prosseguida em ações políticas, ela é uma etapa importante. Para atender esse momento, a proposta mais conhecida é a formulada por Cornell e amplamente adaptada no ensino da Educação Física em ambientes formais e informais. (RIBEIRO, 1997; PEREIRA, 2004). Cornell (1996) desenvolve sua proposta de Aprendizado Sequencial por meio de quatro estágios. Primeiro se desperta ludicamente o entusiasmo, para depois focar a atenção sobre a atividade, seguido pela transformação da atividade em experiência dirigida a uma descoberta que, por fim, é compartilhada. Essa metodologia é promissora se for capaz de transcender da subjetividade e da sensibilidade para uma consciência coletiva e concreta.

Potencial que também se almeja alcançar nas ditas atividades físicas de aventura na natureza (AFAN), as quais se multiplicaram na história contemporânea, sendo prontamente capitalizadas como mercadorias do setor turístico de aventura. Não obstante os discursos inocentemente úteis sobre as AFAN como educação, como contraponto ao esporte hegemônico e forma de aproximação com a natureza, a realidade mostra que boa parte dos praticantes está mais interessada na fruição da atividade, tomando a natureza como uma fuga do cotidiano.

Considerando tais limites nas AFAN, vale ressaltar que ainda são recentes as reflexões e propostas de tomada dessas práticas corporais no corpo de conhecimentos da Educação Física. Aliás, é até ambíguo definir se podem ser enquadradas como esportes tão somente ou se é 
possível pensar em ginásticas, danças, lutas e jogos na natureza. Constituem certamente um conteúdo importante para ser pensado na escola e a viabilidade de sua implantação passa tanto pela oferta de disciplinas nos currículos como, também, por uma reformulação da escola, tomando o meio ambiente como necessidade de debate permanente. Em termos ambientalistas, caso as AFAN não sejam tomadas como problema educacional, a demanda por essas práticas permanecerá predominantemente sujeita a um consumo não-sustentável, reforçando, por sua vez, um trabalho predatório. Entendemos como tratamento educacional o fato de tal atividade ser abordada numa dimensão pedagógica, o que implica numa perspectiva que permitirá ao aluno o conhecimento, a vivência e a transformação do conhecimento, de forma consciente, crítica e participativa.

Vale, em acréscimo, imaginar a quantidade de experiências que poderiam ser criadas, descobertas e até sistematizadas em aulas na e com a natureza. Porém, a realidade é outra:

A educação corporal, por exemplo, atrelada aos currículos da educação física, não estuda as diversas manifestações corporais que acontecem todos os dias nos $8.000 \mathrm{Km}$ de praias do nosso litoral, ou ainda nas centenas de comunidades ribeirinhas escondidas no interior da floresta amazônica. (PEREIRA, 2004, p. 49).

Todavia, a existência de fragmentos de educação corporal voltada para as práticas na natureza é ainda uma ineficiente educação para e pelo lazer. Longe estamos de contemplar uma concepção que tome as AFAN como um conhecimento que enseja outros conhecimentos. É o empobrecimento da prática que, limitada a uma atividade não refletida e consumida numa natureza nobre (praias, montanhas, florestas), ainda não alcançou a condição de objeto e meio de educação.

Mas haveria diferencial nessas práticas a ponto de constituírem um conhecimento diferenciado? Ponderamos que sim. Primeiro porque, em geral, os movimentos não ocorrem de maneira estereotipada. É difícil planejar quais gestos fazer quando se está na natureza, sendo ela um meio imprevisível. Mas, principalmente, porque essas práticas se tornaram novas com o advento de "apetrechos" tecnológicos. Interessante pensar no caso das corridas de orientação, realizadas em equipes. Nelas não basta ter o melhor padrão motor de corrida ou um VO2 
alto, pois a noção de espaço, o uso de bússolas, mapas ou GPS e a cooperação são tão ou mais importantes que a dimensão fisiológica. Afora isso, se poderia tomar a dimensão ecológica (portanto, política e ética) de sua vivência em chácaras, parques e quintais, evidenciando como a natureza se faz presente em nosso meio (fazendo contraponto às AFAN em lugares privados).

\section{Possíveis relações entre Lazer, Meio Ambiente e Educação Física Escolar}

Outro tratamento importante é que o Lazer e o Meio Ambiente sejam abordados nas aulas de Educação Física como possibilidades de vivência diversificada e apropriação de conhecimento . Trata-se de familiarizar essa relação ao cotidiano do sujeito em comunidade, na sua relação consigo (cuidado de si) e com os outros.

Obviamente, não é o caráter utilitarista do Lazer e do Meio Ambiente que desejamos explorar, mas a partir deles conferir significados, conceitos e conhecimentos para vida dos alunos, que podem ampliar tais noções, se na fase anterior as experiências com o Lazer e o Meio Ambiente foram cultivadas.

A partir de tais considerações propomos uma relação mais intensa entre Lazer, Meio Ambiente e Educação Física Escolar. Para tanto, sugerimos algumas situações que favoreçam tal vinculação.

Considerando que para cada nível de ensino faz-se necessária uma adequação, discutiremos a Educação Infantil e Séries Iniciais do Ensino Fundamental, separada das Séries Finais do Ensino Fundamental e, por sua vez, esta separada do Ensino Médio.

Educação Infantil e Séries Iniciais do Ensino Fundamental

Inicialmente precisamos destacar qual o entendimento que temos sobre o que a Educação Física na Educação Infantil. Dessa forma, partimos do princípio que:

A Educação Infantil e as séries iniciais do Ensino Fundamental não devem ser o momento de preparação e iniciação de manifestações culturais esportivas, mas o local para a formação corporal suficientemente adequada para que o indivíduo, dentro de suas condições, escolha a forma como quer movimentar-se. (MOREIRA; PEREIRA; LOPES, 2009a, p. 119) 
Dessa forma, quanto mais organizadas e diversificadas forem as atividades das aulas de Educação Física na Educação Infantil e Séries Iniciais do Ensino Fundamental mais significativas serão, pois a prática da Educação Física na escola tem os mesmos objetivos de outros componentes curriculares, ou seja, buscam desenvolver as potencialidades humanas. (GALLARDO; OLIVEIRA; ARAVENA, 1998).

Optamos por iniciar nossas proposições para a Educação Infantil e Séries Iniciais do Ensino Fundamental abordando os temas: brincadeiras populares e de rua, por entendermos que estes oferecem vivências significativas para os alunos desse nível de ensino.

Uma simples brincadeira de esconde-esconde ganha mais intensidade e emoção quando realizada em ambientes que tenham árvores, arbustos, valas, buracos, dentre outras condições físicas, algo muito comum em espaços que a escola muitas vezes não dispõe. Para aquelas que dispõem dessa estrutura, o aproveitamento precisa ser otimizado.

Conduzir as crianças em atividades em ambientes distintos da escola e, consequentemente, sua estrutura arquitetônica petrificada e aprisionadora, em espaços que possam realizar movimentos diferentes dos que realizam numa quadra e entendam essa diversificação, tanto de movimentos como de ambientes, como algo benéfico ao seu processo de formação.. Significa dizer que desde cedo estimular-se-ão as crianças para que exijam, busquem, encontrem locais que permitam realizar suas manifestações corporais de forma livre, espontânea e adequadas à sua condição.

O aluno ainda pode, a partir dessa situação, identificar possibilidades de se movimentar em ambientes diversos e que poderão gerar uma satisfação maior ao perceber que existem outras possibilidades para além daquelas comumente utilizadas na escola.

Vale ressaltar ainda que tais práticas permitirão a preservação da cultura popular, agregada à condição do sentimento de pertença e de tomar parte do ambiente em que a atividade se realiza e que outrora poderá ser realizada.

Essa condição apresentada, além dos estímulos físico-motores, cognitivos e sociais, permitirá à criança colocar-se frente a ambientes que requerem cuidado, admiração, respeito, não no sentido da preservação, mas de ser parte do meio.

Iniciado nessa fase do processo de escolarização, torna-se menos complexo aprofundar-se nesses aspectos posteriormente. 
Séries Finais do Ensino Fundamental

Adotando o mesmo princípio do nível anterior, nas Séries Finais do Ensino Fundamental espera-se que os alunos possam:

[...] resgatar o que já foi apreendido e assimilado pelas crianças, procurando trazê-los para o contexto atual em que se encontram. Esses conteúdos/ conhecimentos serão retomados, re-estruturados e ampliados a partir de uma nova perspectiva. (MOREIRA; PEREIRA; LOPES, 2009b, p. 154).

Nessa fase, os alunos tendem a romper com tudo o que os aproximam da infância, pois desejam transcender para a etapa seguinte de suas vidas, a adolescência.

Propomos que alguns períodos (dois, três, cinco, sete dias) pelo menos durante o horário das aulas, os alunos não utilizem aparelhos de telefone celular, nem relógios, algo muito presente no cotidiano de boa parte da população, desde muito cedo.

A partir de então, o professor conduz a reflexão de como o contexto social domina, impõe e cria necessidades que, de fato, não são necessárias. Nesse sentido, já se busca um processo educativo contra-hegemônico, no qual o aluno reconhece o modo vigente de produção e reprodução da vida material explora múltiplas dimensões do ambiente (o trabalhador, os recursos naturais, a cidade, os espaço de lazer).

Tal perspectiva pode ser explorada nas aulas de Educação Física, mas também em qualquer componente curricular, visto as inúmeras possibilidades de discussão: a emissão de poluentes; a produção em massa de aparelhos de telefone celular; o controle que o tempo exerce sobre a vida das pessoas; a necessidade de chegar nos locais com a maior rapidez possível e os impactos causados ao Meio Ambiente a partir de tais necessidades (emissão de poluentes, rios poluídos, poluição sonora, trânsito caótico, imprudência no trânsito, dentre outras); a falta de tempo que não permite pensarmos em atividades com ênfase no prazer e satisfação, bem como o simples fato de "não fazer nada", inclusive não atender uma ligação do aparelho de telefone celular.

Sabemos que o consumismo e a rotina que a sociedade e, consequentemente, as crianças e adolescentes enfrentam dificultará tais reflexões, mas é algo necessário, permitindo que desde cedo crianças e 
adolescentes pensem numa maneira de ocupar seu tempo, em realizar práticas corporais que lhe satisfaçam sem que necessariamente tenham um momento e tempo exatos para ocorrer/ acontecer.

As aulas de Educação Física podem assumir a responsabilidade de oferecer atividades que não explorem a dimensão linear de horário/ tempo, mesmo sabendo que a escola, bem como toda sociedade, se orienta por esse paradigma. Porém, a educação não pode se pautar pela mera adaptação. É necessário encontrar as ditas brechas para ruptura e transformação.

Em relação a esse questionamento, é necessário oportunizar situações de contemplação, apreciação, interpretação, análises e estabelecimento de valores são fundamentais para formação de um indivíduo crítico, participativo e consciente de seus direitos e deveres de cidadão. Retornando aos PCNs, que associam meio ambiente e saúde, não seria o caso de 'desnaturalizar' as causas do estresse crônico? Quanto mais aumentamos a velocidade de nossas ações cotidianas, menos nos apossamos delas e mais buscamos o lazer como uma compensação aos desgastes provocados pela correria.

Essa reificação da relação utilitarista com o tempo, como algo inevitável, poderia provocativamente ser repensado em nossos gestos. Para tanto, é válido propor atividades em locais onde os aparelhos de telefone celular não funcionem, atividades que requerem relações humanas com o Meio Ambiente em que o tempo é o que menos importa, permitindo criar uma dinâmica que extrapole a lógica atual:

- Brincar até cansar!

- Caminhar até cansar!

- Correr até cansar!

- Perder a hora e ficar feliz com isso!

- Dormir até acordar!

- Esquecer de almoçar!

Enfim, longe de deambulações contraproducentes, é fundamental construir dinâmicas provocativas que a escola e as aulas de Educação Física possam oferecer "hoje" e que servirão para o cotidiano presente e futuro dos alunos.

Ressaltamos que redimensionar a compreensão do Meio Ambiente como pura exterioridade requer mais do que uma ação isolada, num determinado período de tempo, mas sim com ações contínuas, sejam nas aulas de Educação Física ou em atividades integradas a outros componentes curriculares e mesmo ao projeto pedagógico da escola. 
Ações contínuas atreladas ao trabalho desenvolvido na etapa anterior, pode redimensionar a compreensão do Meio Ambiente como parte da existência humana.

\section{Ensino Médio}

Entendemos que a prática da Educação Física no Ensino Médio deve ser repensada, discutida, refletida, visto os problemas recorrentes que identificamos em diversas pesquisas nesse nível de ensino. Para tanto, indicamos que:

[...] a prática da Educação Física no Ensino Médio aponta uma necessidade urgente de repensar seus conteúdos e os processos didático-pedagógicos de ensino e, principalmente, a importância de dar vez e voz aos alunos desmotivados [...]. (MOREIRA; PEREIRA; LOPES, 2009c, p. 179)

Oliveira (2004) afirma que o Ensino Médio deve oferecer subsídios para que os alunos tenham a possibilidade de fomentar a prática da atividade física, mediante o conhecimento de seu acervo motor de forma autônoma. Contudo, a aquisição dessa autonomia depende das discussões estabelecidas em aula com os professores e os alunos.

Dessa forma, esse nível de ensino, por sua característica desafiadora, considerando o atendimento de indivíduos na fase da adolescência, deve extrapolar as situações vividas até então, mas sempre num processo contínuo e gradativo de desenvolvimento das atividades e estímulo a conquista da autonomia.

Sugerimos que a escola e não apenas as aulas de Educação Física levem os alunos a uma relação mais íntima e por que não intimista com o Lazer e o Meio Ambiente. No ensino médio, muitos alunos, especialmente na escola pública, já se direcionam ao mundo do trabalho, onde estabelecerão novas relações com o meio. Por tendência, aumentará o estranhamento enquanto o tempo livre será restringido.

Propor caminhadas, corridas, passeios ciclísticos, esportes de aventura, em ambientes "naturais" é algo que chamará atenção desses alunos. Como afirmam Inácio e Marinho (2007), embora não representem uma superação do sistema, as práticas corporais de aventura na natureza possibilitam certo distanciamento do cotidiano, incluindo as sensações e gestos do dia-a-dia. Dado esse diferencial, estariam am- 
pliadas tanto a alienação quanto as possibilidades de se desenvolver o auto-conhecimento e a mudança de atitudes.

Contudo, ressaltamos o que fora abordado anteriormente, ou seja, se as relações entre Lazer, Meio Ambiente e Educação Física Escolar forem abordadas desde o início da Educação Básica de forma adequada e constante, de maneira disciplinar ou integrada a projetos maiores da escola, a abordagem e aprofundamento dessa temática no Ensino Médio torna-se menos complexa.

Mais importante do que a prática propriamente dita, é a possibilidade de refletir sobre o que se faz, por que se faz e para que se faz, ou seja, que conhecimentos e relações os alunos estabelecerão com a condição vivenciada.

Dessa forma, caso não haja uma direção desde o início da Educação Básica, tais atividades podem ficar limitadas ao seu caráter utilitarista: usar o espaço e voltar para a "selva de pedra" e tocar a vida "normalmente". Para ilustrar, por conta dos riscos inerentes a algumas práticas, se percebe a oferta de modalidades de aventura na natureza, preferencialmente na moda, mas os operadores dessas atividades não possuem preparação pedagógica e tampouco os professores fazem as relações teóricas necessárias para ultrapassar a experiência de exaltação sensorial para uma reflexão mais efetiva.

Perceber o local em que se está, reconhecê-lo, respeitá-lo; reconhecer-se como parte deste espaço e não como "senhor dele"; identificar a importância do local para si e para os outros; reconhecer o espaço como um ambiente em que a satisfação e os anseios podem ser atendidos, em que a contemplação é mais importante do que o tempo que dispomos; reconhecer este espaço como a casa de um parente ou amigo e que pode ser visitada várias vezes, desde que o respeito e a liberdade sejam mantidos; por fim, reconhecer que a vivência de tais atividades pode transcender o período em que permanecemos na escola, isto é, por toda vida. Essas atitudes, por sua vez, devem estar articuladas a um movimento maior de mudança nas estruturas da sociedade, visando a superação do atual modelo de desenvolvimento.

\section{Considerações finais}

Talvez o leitor esperasse por "fórmulas" ou "modelos" que pudessem responder imediatamente às dificuldades em relacionar Lazer, Meio Ambiente e Educação Física Escolar. Contudo, é contraprodu- 
cente ditar os fazeres pedagógicos de cada um. Assim, propusemos reflexões que permitirão a cada docente transcender sua própria prática, a partir de um olhar para sua realidade e não tente utilizar modelos que por ventura tenham obtido êxito. De fato, não foi essa nossa intenção.

Entendemos que o lazer é uma invenção social, tomado como direito social graças à mobilização dos trabalhadores. Como tal é pago pelo trabalho e, logo, decorre como usufruto da forma como as pessoas coletivamente transformam a natureza. No tempo livre, quando optamos pelo lazer, produzimos e consumimos a cultura. Essa relação é afetada por diversos fatores, sendo a educação um desses determinantes. Por isso, temos defendido que tanto na escola quanto em projetos esportivos sociais é possível educar para o lazer e, mais especificamente, para vivenciar o lazer na natureza (PIMENTEL, 2011) ou, de forma mais ampla, numa perspectiva ambiental. (PIMENTEL; PEREZ, 2009).

Esse tipo de educação parte de princípios simples como tomar o meio ambiente como o lugar onde se vive e convive. Logo, a escola pode ser o primeiro lugar de interface entre a Educação Física, Lazer e Meio ambiente. Algumas questões podem ilustrar essa idéia: $O$ lixo da escola é reciclado? As crianças têm contato com árvores no recreio? A posição do bloco favorece a luz natural? Como envolver todos os alunos para planejar a acessibilidade dos alunos paraplégicos à aula? Os alunos conseguem aplicar conhecimentos aprendidos na aula de Educação Física quando possuem a oportunidade de tomar banho de rio ou se fizerem uma trilha no fim de semana? Ou melhor: a Educação Física estabelece relações e interações com o Lazer e o Meio Ambiente? E essas interações tomam o ambiente como uma natureza do tipo 'paisagem' ou leva o aluno a entender como as condições ambientais de sua casa, bairro e cidade interferem no seu acesso ao lazer e às práticas corporais?

Tomemos um exemplo que foge ao rótulo ecológico no senso-comum, mas é um caso de Educação Física que educa pensando no meio ambiente. Digamos que no ensino fundamental, a professora planeja que seus alunos estudarão os movimentos locomotores. Ela solicita que memorizem como necessitam ou podem se deslocar em seu bairro conforme o tipo de local (casa, rua da casa, rua do comércio, praça). Essa professora pode solicitar aos alunos que demonstrem os movimentos utilizados em cada contexto, identificando se o ambiente fre- 
quentado pelas crianças é favorável, ou não, ao universo motor. Também pode buscar as causas de certos movimentos (correr para atravessar a rua sem semáforo, por exemplo). Ainda, pensando na diversificação das práticas no lazer, poderia mediar novas formas de mobilização por mais ambientes para brincar ou novas apropriações para os locais já existentes.

Para tanto, a Educação Física seria tomada como importante componente curricular, que ensina conhecimentos da cultura corporal, historicamente situada, cujas práticas seriam selecionadas conforme o contexto sociocultural, mas, também, pelas possibilidades educativas que abriga, numa perspectiva ampliada de formação escolar. Isso significa entender que a escola tem como uma das suas nobres tarefas a formação de sujeitos autônomos que tomarão decisões ambientalmente sustentáveis no seu tempo livre.

Leisure, environment and scholar physical education: is a relationship possible?

\begin{abstract}
This paper discusses relationships and able to be achieved between leisure, environment and scholar Physical Education. For this, ponder about the need to understand the environment in the condition of local where one lives. Consequently, the Physical Education may initially treat their pedagogical content in relation to the concrete challenges really presents in the community life. From this perspective, we discuss this learning since the school, offering specifics directives on all your levels.
\end{abstract}

Keywords: Leisure Activities. Environment. Education Primary and Secondary.

Ocio, medio ambiente y educación física: relaciones posibles?

\title{
Resumen
}

Este ensayo analiza determinadas relaciones entre ocio, medio ambiente y Educación Física en las escuelas, considerando sus posibilidades reales. Hacia lo mismo, se reflexiona sobre la necesidad de entender que el medio ambiente es la realidad donde se vive. En consecuencia, la Educación Física inicialmente puede tratar su contenido pedagógico con relación a los desafíos concretos en la vida comunitaria. Desde esta perspectiva, se discute este aprendizaje desde la escuela, con acciones pertinentes en uno de los niveles de la educación.

Palabras clave: Actividades Recreativas. Ambiente. Educación Primaria y Secundaria. 


\section{Referências}

CORNELL, J. Brincar e aprender com a natureza. São Paulo: Melhoramentos: Senac, 1996.

FERREIRA, D. M. Uma floresta encantada. Escola Estadual Professor Helon Gomide. Trindade - GO. III Concurso de Poesia (Projeto Cidadania Ambiental - PCA) Disponível em: <http://www.apoema.com.br/poemaecologico.htm>. Acesso em 11 jan. 2011.

FOSTER, J. B. A ecologia de Marx: materialismo e natureza. Rio de Janeiro: Civilização Brasileira, 2005.

GAllardo, J. S.; OLIVEIRA, A. A. B. de; ARAVENA, C. J. O. Didática de educação física: a criança em movimento: jogo, prazer e transformação. São Paulo: FTD, 1998.

INACIO, H.; MARINHO, A. Educação física, meio ambiente e aventura: um percurso por vias instigantes. Revista brasileira de ciências do esporte, Campinas, v. 28, n. 3, p. 55-70, maio, 2007.

MOREIRA, E. C.; PEREIRA, R. S.; LOPES, T. C. Considerações, reflexões e proposições para a educação física na educação infantil e séries iniciais do ensino fundamental. In: MOREIRA, E. C.; NISTAPICCOLO, V. L. (Orgs.). O quê e como ensinar educação física na escola. Jundiaí, SP: Fontoura, 2009a. p. 109-149.

. Consolidando caminhos e caminhadas da educação física nas séries finais do ensino fundamental. In: MOREIRA, Evando C.; NISTA-PICCOLO, Vilma L. (Orgs.). O quê e como ensinar educação física na escola. Jundiaí, SP: Fontoura, 2009b. p. 151-175.

. Desafios e propostas para a educação física no ensino médio. In: MOREIRA, E. C.; NISTA-PICCOLO, Vilma L. (Orgs.). O quê e como ensinar educação física na escola. Jundiaí, SP: Fontoura, 2009c. p. 177-197.

OLIVEIRA, A. A. B. de. Planejando a educação física escolar. In: VIEIRA, J. L. L. (Org.). Educação física e esportes: estudos e proposições. Maringá, PR: Eduem, 2004. p. 25-56. 
PEREIRA, V. Caminhada ecológica: percepções e significados sobre a experiência na trilha. Mestrado em Ciências do Movimento Humano. 2004. 125 f. (Dissertação)-Centro de Educação Física, Fisioterapia e Desportos, Universidade do Estado de Santa Catarina, Florianópolis, 9 dez. 2004.

PIMENTEL, G. G. de A. A insustentabilidade do lazer sustentável. In: MÜLLER, Ademir; DA COSTA, Lamartine. (Orgs.). Lazer e desenvolvimento regional. Santa Cruz do Sul-RS: Editora da UNISC, 2002, p. 83-107.

. Aventuras de lazer na natureza: o que buscar nelas? In: MARINHO, A.; BRUHNS, Heloisa. (Orgs.). Viagens, lazer e esporte. Barueri, SP: Manole, 2006, p. 43-73.

. Educação Física escolar e lazer: ações e reflexões. In: MOREIRA, E. C.; PEREIRA, R. S. (Orgs.). Educação física escolar: desafios e proposta 2. 2. ed. rev. e ampl. Jundiaí-SP: Fontoura, 2011. p. $105-117$.

PIMENTEL, G. G. de A; PEREZ, D. Meio ambiente como tema gerador. In: OLIVEIRA, A. A. B.; PIMENTEL, G. G. de A. (Orgs.). Recreio nas férias: reconhecimento do direito ao lazer. Maringá, PR: Eduem, 2009. p. 51-66.

RIBEIRO, I. Perspectivas ecológicas da educação corporal: rumo à qualidade total de vida. Motriz, São Paulo, v. 3, n. 2, p. 116-122, dez., 1997.

SOUZA, M. da S.; LARA, G. S. Prática pedagógica em educação física e a educação ambiental. Pensar a Prática, Goiânia, v. 14, n. 2, p. 1-11, maio/ago., 2011.

Recebido em: 17/10/2011

Revisado em: 20/01/2012

Aprovado em: 04/03/2012

Endereço para correspondência

ecmmorera@uol.com.br

Evando Carlos Moreira

Universidade Federal de Mato Grosso

Faculdade de Educação Física. 
DOI 10.5216/rpp.v16i1.15971

Av. Fernando Correa da Costa, $\mathrm{s} / \mathrm{n}^{\mathrm{o}}$

Coxipó

78100-900 - Cuiabá, MT - Brasil

Pensar a Prática, Goiânia, v. 16, n. 1, p. 1-319, jan./mar. 2013 